\title{
Релаксационная кинетика фотоэмиссии из GaAs со слоями цезия
}

\author{
В.С. Хорошилов ${ }^{1,2)}$, А.Г. Журавлев ${ }^{1,2)}$, Д.М. Казанцев ${ }^{1,2)}$, В.Л. Альперович ${ }^{1,2)}$ \\ ${ }^{1}$ Институт физики полупроводников им. А.В.Ржанова СО РАН, 630090, Новосибирск \\ ${ }^{2}$ Новосибирский государственный университет, 630090, Новосибирск \\ тел:+7 (383)330-98-74, эл. nочта: zhuravl@isp.nsc.ru
}

DOI 10.34077/RCSP2019-131

Поверхности $p$-GaAs c адсорбированными слоями цезия и кислорода уже более полувека широко используются для создания фотокатодов с отрицательным электронным сродством [1]. Поверхности полупроводников с относительно небольшим (0.2-0.4 эВ) положительным электронным сродством привлекают внимание в связи с возможностью создания новых преобразователей солнечной энергии, более эффективных, чем фотовольтаические, за счёт использования фотонно-усиленной термоэлектронной эмиссии [2]. Арсенид галлия перспективен для создания таких преобразователей благодаря оптимальной ширине запрещённой зоны и возможности получения оптимального электронного сродства путём нанесения на поверхность $\mathrm{GaAs}(001)$ цезиевого покрытия. Практическое использование поверхности $\mathrm{Cs} / \mathrm{GaAs}$ осложняется её неравновесностью, приводящей к нестабильности фотоэмиссионных свойств из-за необратимых релаксационных процессов в цезиевом слое [3]. Скорость и амплитуда релаксационных изменений тока фотоэмиссии на поверхности $\mathrm{Cs} / \mathrm{GaAs}(001)$ должна существенно зависеть от температуры. Ожидается, что повышение температуры приведет к увеличению скорости и уменьшению амплитуды релаксационной кинетики в результате создания более равновесного цезиевого слоя на поверхности $\mathrm{GaAs}(001)$ при повышенных температурах. В данной работе проведено экспериментальное исследование кинетики тока фотоэмиссии при адсорбции цезия и последующей релаксации Сs слоя на поверхности $\mathrm{GaAs}(001)$ при различных температурах.

Эксперименты проводились в сверхвысоковакуумной установке на эпитаксиальных слоях сильнолегированного $p$-GaAs с концентрацией дырок $7 \times 10^{18} \mathrm{~cm}^{-3}$. Чистые поверхности $\operatorname{GaAs}(001)$ приготавливались химическим удалением оксидов и последующим отжигом в вакууме. Экспериментально установлено, что при увеличении температуры до $150^{\circ} \mathrm{C}$, качественно меняется форма дозовых зависимостей квантового выхода фотоэмиссии: вместо максимума фототока при цезиевом покрытии $\sim 0.5$ ML и последующего падения, при высоких температурах наблюдается насыщение квантового выхода. Данное насыщение, по-видимому, вызвано насыщением изгиба зон при высоких температурах [3]. Сохранение характерных особенностей в дозовых зависимостях фототока свидетельствует, что коэффициент прилипания цезия на поверхности $\mathrm{GaAs}(001)$ с ростом температуры меняется не более, чем на $5 \%$. Кинетика фотоэмисси при последующей релаксации цезиевого слоя, будучи направленной в сторону роста фототока при комнатной температуре, при нагревании становится немонотонной (с несколькими максимумами и минимумами). Такие изменения формы говорят о том, что кинетика обусловлена различными процессами, по-разному зависящими от температуры. По-видимому, рост фототока при релаксации в диапазоне «низких» температур $20^{\circ} \mathrm{C}-80^{\circ} \mathrm{C}$ обусловлен релаксацией истинного сродства, а падение при «высоких» температурах $80^{\circ} \mathrm{C}-150^{\circ} \mathrm{C}$ - релаксацией изгиба зон. В настоящей работе кинетика фототока описывалась с помощью трёх экспоненциальных слагаемых. Характерные времена релаксации, определенные из экспериментальных кинетик, лежат в диапазоне от 20 секунд до 30 минут. Установлено, что при релаксации цезиевого слоя характерные времена кинетики снижаются с ростом температуры, что может быть связано с ускорением релаксационных процессов. В работе также обсуждается возможность повышения стабильности цезиевого покрытия путём адсорбции кислорода на поверхности $\mathrm{Cs} / \mathrm{GaAs}$.

Исследование выполнено при финансовой поддержке РФФИ и Правительства Новосибирской области в рамках научного проекта № 18-42-543005.

\section{Jumepamypa}

[1] V.V. Bakin et al., e-J. Surf. Sci. Nanotech. Vol. 5, p.80-88 (2007).

[2] J.W. Schwede et al., Nat. Mater. 9, 762 (2010).

[3] A.G. Zhuravlev, V.L. Alperovich, Appl. Surf. Sci. 395, 3 (2017). 